\title{
LA INICIATIVA LEGISLATIVA POPULAR EN LAS COMUNIDADES AUTÓNOMAS. LA NECESARIA REFORMA DE SU LEGISLACIÓN
}

\author{
VICENTE CABEDO MALLOL \\ Profesor de Derecho Constitucional \\ Universidad Politécnica de Valencia
}

\section{SUMARIO}

I. Introducción: la participación ciudadana en el proceso legislativo autonómico.

II. El desarrollo de la iniciativa legislativa popular en el ámbito estatal y autonómico.

III. Balance de la institución de la iniciativa popular.

IV. La reforma de la LO 3/1984, reguladora de la iniciativa legislativa popular y la nueva ley catalana $1 / 2006$, de la iniciativa legislativa popular. Las restricciones de las legislaciones autonómicas.

V. A modo de conclusión.

\section{INTRODUCCIÓN: LA PARTICIPACIÓN CIUDADANA EN EL PROCESO LEGISLATIVO AUTONÓMICO}

La democracia representativa o electoral inspira, sin duda, la Constitución española de 1978. Sin embargo, en la misma podemos encontrarnos con instituciones clásicas de democracia directa, como son el referéndum (art. 92) o la iniciativa legislativa popular (art. 86.3). Manifestaciones de democracia directa que, como apunta Francisco Astarloa ${ }^{1}$, apenas han llamado la atención de la doctrina del Derecho constitucional.

1 ASTARLOA VILLENA, F., "La iniciativa legislativa popular en España", en Teoría y Realidad Constitucional, núm 10-11, 2002-2003, pág. 273

UNED. Teoria y Realidad Constitucional, núm. 24, 2009, pp. 455-476. 
La participación ciudadana en los asuntos públicos, directamente o por medio de representantes, es la esencia de una democracia. Nuestra Carta Magna configura esta participación como un derecho fundamental de los ciudadanos (art. 23.1), y encomienda a los poderes públicos facilitar su participación en la vida política, económica, cultural y social (art. 9.2).

Esta previsión del artículo 9.2 de la Constitución es recogida por la mayoría de los Estatutos de Autonomía ${ }^{2}$ a excepción de los de Canarias y de Navarra. Por otra parte, las últimas reformas estatutarias han incidido, en mayor medida, en la participación ciudadana, reconociéndose expresamente en algunos Estatutos el derecho o derechos de participación (art. 15 del Estatuto de Autonomía de Aragón; art. 11 del Estatuto de Castilla y León; art. 29 del Estatuto de Cataluña; y art. 15 de Estatuto de las Islas Baleares), o la participación política (art. 30 del Estatuto de Andalucía). El proyecto de reforma del Estatuto de Castilla-La Mancha contempla, en su artículo 10.3, los Derechos de ciudadanía.

Centraremos nuestra atención en el desarrollo del derecho a la participación ciudadana en el ámbito legislativo autonómico y, más concretamente, en la iniciativa legislativa popular.

La participación ciudadana en el ámbito legislativo tiene, además de una fundamentación jurídico-constitucional, una fundamentación social y políticofilosófica ${ }^{3}$. La lejanía o distanciamiento de las personas elegidas democráticamente como nuestros representantes justificaría la necesidad de potenciar la participación directa.

Siguiendo a Fernando Pindado ${ }^{4}$, podemos analizar la participación según el grado de actividad desarrollado por las personas que lo ejercitan. El nivel más bajo de actividad es aquél en el que se consulta a la ciudadanía y ésta opina. Los nuevos Estatutos de Cataluña, de Aragón, de Andalucía y de Castilla y León han previsto, en sus artículos 122, 71. 27. a, 78 y 75.15. a, respectivamente, las consultas populares como materia de competencia exclusiva de sus Autonomías, a excepción del referéndum (competencia exclusiva del Estado, de acuerdo el art. 149.1.32 de la Constitución). Por su parte, el nuevo Estatuto de la Comunidad Valenciana limita las consultas populares al ámbito municipal (art. 50.8). El proyecto de reforma estatuaria de Castilla-La Mancha también prevé, sin la limitación valenciana, las consultas populares.

Otro grado más activo de participación sería el derecho de petición. Este derecho se reconoce en el art. 29 de la Constitución española y en los Esta-

2 Vid. Art. 10.1 del E.A. de Andalucía; art. 15.3 del E.A. de Aragón; art. 9.2.e) del E.A. de Asturias; art. 15.2.b) del E.A. de las Islas Baleares; art. 5.2 del E.A. de Cantabria; art. 4.2 del E.A. de Castilla_ La Mancha; art. 8.2 del E.A. de Castilla y León; art. 4.2 del E.A. de Cataluña; art. 9.4 del E.A. de la Comunidad Valenciana; art. 6.2.c) del E.A. de Extremadura; art. 4.2 del E.A. de Galicia; arts. 1.3, 7.4 y 26.1.25 del E.A. de Madrid; art. 9.2.e) del E.A. de Murcia; art. 7.2 del E.A. de La Rioja; y art. 9.2.e) del E.A. del País Vasco.

3 Vid. PINDADO SÁNCHEZ, F., "El desenvolupament del dret a la participació en l'àmbit legislatiu", en Activitat parlamentària, Núm 11, febrero, 2007, págs. 21 y 22.

4 Ibidem, págs. 24. 
tutos de Autonomía de Andalucía (art. 30.1.d)), Aragón (art.16), Baleares (art. 15.2.d)), Cataluña (art. 29,5) y Castilla y León (art. 11.6). La Comunidad de Castilla-La Mancha, en su proyecto de reforma estatutaria, contempla también este derecho.

Un nivel más elevado de actividad de la ciudadanía en el ámbito legislativo nos lo proporcionaría la participación en la elaboración de las leyes, directamente o mediante entidades asociativas (art. 30.1.2 del Estatuto de Andalucía; art. 15.2 del Estatuto de Aragón; art. 15.2.b) del Estatuto de las Islas Baleares; y art. 29.4 del Estatuto de Cataluña). Pero, sin duda alguna, el nivel más intenso de participación ciudadana nos lo brinda la institución de la iniciativa legislativa popular; institución prevista en el art. 86.3 de la Constitución española y en todos los Estatutos de Autonomía de las diversas Comunidades Autónomas.

\section{EL DESARROLLO DE LA INICIATIVA LEGISLATIVA POPULAR EN EL ÁMBITO ESTATAL Y AUTONÓMICO.}

\section{II.1. La iniciativa legislativa POPUlaR EN LA CONSTituCión y EN lOS Estatutos DE Autonomía}

El artículo 86.3 de la Constitución, con relación a la iniciativa legislativa popular, señala: "Una ley orgánica regulará las formas de ejercicio y requisitos de la iniciativa popular para la presentación de proposiciones de ley. En todo caso se exigirán no menos de 500.000 firmas acreditadas. No procederá dicha iniciativa en materias propias de ley orgánica, tributarias o de carácter internacional, ni en lo relativo a la prerrogativa de gracia". La institución prevista en dicho precepto se desarrolló por Ley Orgánica 3/1984, de 26 de marzo, reformada por Ley Orgánica 4/2006, de 26 de mayo.

A nivel autonómico, los diecisiete Estatutos de Autonomía también han previsto la iniciativa legislativa popular ${ }^{5}$, remitiendo su desarrollo a las respectivas leyes autonómicas sobre la materia, que determinan las condiciones para su ejercicio. Todos los Estatutos, excepto el de Cataluña y el de La Rioja, prescriben que la iniciativa legislativa corresponde, por una parte, a los miembros (Diputados o Procuradores) y, en su caso, a los grupos parlamentarios de la Asamblea legislativa (Parlamento, Cortes o Corts); y, por otra, al

5 El Estatuto de Castilla y León era, hasta la reforma estatutaria operada por la Ley Orgánica 4/1999, el único que no contemplaba la iniciativa legislativa popular. En la actualidad todos los Estatutos de Autonomía recogen dicha iniciativa legislativa. Vid. Art. 30.1.b y 111.2 del E.A. de Andalucía; art. 15.2 del E.A. de Aragón; art. 31.1 del E.A. de Asturias; art. 15.2.b del E.A. de las Islas Baleares; art. 12.5 del E.A. de Canarias; art. 15.1 del E.A. de Cantabria; art. 12.1 del E.A. de Castilla_ La Mancha; art. 25.2 del E.A. de Castilla y León; art. 62.1 del E.A. de Cataluña; art. 26.2 del E.A. de la Comunidad Valenciana; art. 23.2 del E.A. de Extremadura; art. 13.1 del E.A. de Galicia; art. 15.2 del E.A. de Madrid; art. 30.1 del E.A. de Murcia; art. 19.2 del E.A. de Navarra; art. 20 del E.A. de La Rioja; y art. 27.4 del E.A. del País Vasco. 
Consejo de Gobierno (Junta, Junta General, Gobierno o Consell). A continuación unos Estatutos señalan que la iniciativa legislativa popular (o iniciativa popular) para la presentación de proposiciones de Ley se regulará mediante Ley por la respectiva cámara legislativa (Asamblea, Parlamento, Cortes o Corts); otros, en cambio, que por ley (o una ley) de dicha cámara se podrá regular (o se regulará) el ejercicio de la iniciativa legislativa popular. Es criticable que no se indique desde el primer momento que la iniciativa legislativa también corresponde, además de a la Asamblea legislativa y al Consejo de Gobierno, a los ciudadanos a través de la iniciativa popular.

La previsión más criticable de la iniciativa popular es, sin duda alguna, la del nuevo Estatuto de Autonomía de la Comunidad Valenciana. Su artículo 26.2 establece que "La iniciativa legislativa de Les Corts se ejercerá por los Grupos Parlamentarios y por los Diputados y Diputadas en la forma que determine el Reglamento de Les Corts. También podrá ser ejercida a través de la iniciativa popular en la forma que se regule por Ley y en los términos previstos en el Reglamento de Les Corts" (art. 26.2). Si leemos detenidamente el precepto trascrito, se está indicando que la iniciativa legislativa de Les Corts se ejercerá por los Grupos Parlamentarios, por los Diputados y Diputadas y a través de la iniciativa popular. Ello concuerda con el punto primero de este artículo que prescribe que la iniciativa legislativa corresponde únicamente a Les Corts y al Consell. Al incardinar o subsumir la iniciativa popular en la iniciativa legislativa de Les Corts se está subordinando la democracia participativa a la democracia representativa.

El Estatuto de Autonomía de Cataluña, por su parte, en su art. 62.1, señala que "La iniciativa legislativa corresponde a los Diputados, a los grupos parlamentarios y al Gobierno. También corresponde, en los términos establecidos por las leyes de Cataluña, a los ciudadanos, mediante la iniciativa legislativa popular, y a los órganos representativos de los entes supramunicipales de carácter territorial que establece el presente Estatuto". Este precepto, al contrario que el valenciano, sitúa al mismo nivel las diversas iniciativas legislativas.

En parecidos términos al Estatuto catalán, el de La Rioja indica que la iniciativa legislativa corresponde a los Diputados, al Gobierno y al pueblo riojano (art. 20).

Por otra parte, es cuanto menos llamativo que la Comunidad de Extremadura sea la única Comunidad Autónoma que fija en su Estatuto el tanto por cien de firmas acreditadas necesarias, que sitúa en el 5\% del censo electoral, para avalar una iniciativa popular (art. 23.2). La otras Comunidades, con buen criterio, determinan el número de firmas necesarias en las respectivas Leyes autonómicas que regulan la iniciativa legislativa popular.

También es importante destacar que el Estatuto de Autonomía catalán va incluso más allá del reconocimiento de iniciativa legislativa popular (art. 29.3), al señalar que los ciudadanos de Cataluña con derecho a voto pueden proponer al Parlamento que ejerza la iniciativa de reforma del Estatuto. Esta propuesta necesita contar, en todo caso, con 300.000 firmas (arts. 222.1 y 223.1 del Estatuto de Cataluña). 


\section{II.2. LA LEGISLACIÓN AUTONÓMICA SOBRE LA INICIATIVA LEGISLATIVA POPULAR}

Tras la aprobación de la LO 3/1984, las Comunidades Autónomas fueron aprobando sus respectivas Leyes de iniciativa legislativa popular ${ }^{6}$. La primera fue la del Principado Asturias, en 1984, y la última la de la Comunidad de Castilla y León, en el año 2001.

En términos generales, nos comenta Víctor Cuesta, la legislación autonómica sobre la iniciativa legislativa ciudadana trasladó miméticamente el modelo establecido por la LO 3/1984. De acuerdo con el estudio comparado que este autor lleva a cabo, "la reproducción de las condiciones subjetivas, formales, procedimentales y materiales va mucho más allá de la debida observancia al contenido esencial de la legislación orgánica estatal y al principio de homogeneidad institucional del art. $152 \mathrm{CE}^{{ }^{7}}$. Mimetismo que el autor atribuye a "un claro síntoma de desidia del legislador autonómico". "Desidia" que yo sustituiría por el sustantivo "temor". El legislador autonómico, al igual que el estatal, es reticente, temeroso, al desarrollo de la participación ciudadana.

Veamos a continuación los requisitos subjetivos, materiales y formales más importantes que establecían las Leyes autonómicas sobre la iniciativa legislativa popular ${ }^{8}$.

Con relación a la titularidad de la iniciativa popular, las leyes autonómicas reservaban el ejercicio de la iniciativa legislativa a los ciudadanos mayores de edad que gocen de la condición política de ciudadano de la respectiva Comunidad; es decir, con vecindad administrativa en cualquiera de sus municipios. En algunas leyes se añade que estos ciudadanos estén inscritos en el censo electoral.

Por otra parte, como ya he adelantado anteriormente, a excepción del Estatuto de Extremadura, la cantidad mínima de electores que deben suscribir y, por tanto, avalar una incitaba legislativa también viene determinada por la legislación de cada Comunidad Autónoma. Se trata siempre de una cantidad fija que oscila entre las 6.000 firmas que prescribe la Ley riojana 2/1985 y las 75.000 de la Ley andaluza 1/1988. El número de firmas requeridas en cada

6 En Asturias, la Ley 4/1984; en Murcia, la Ley 9/1984 (modificada por la Ley 7/2006); en Aragón, la Ley 7/1984; en Navarra, la Ley Foral 3/1985; en Castilla La Mancha, la Ley 2/1985; en La Rioja, la Ley 3/1985; en Cantabria, la Ley 6/1985; en Extremadura, la Ley 7/1985; en Madrid, la Ley 6/de 19 de enero; en Andalucía, la Ley 5/1988; en las Islas Baleares, la Ley 4/1991; en la Comunidad Valenciana, la Ley de 4 de julio.

7 CUESTA LÓPEZ, V. M., Participación directa e iniciativa legislativa del ciudadano en democracia constitucional. Tesis doctoral dirigida por Juan Fernando López Aguilar y Juan Ramón Rodríguez-Drincourt Álvarez.Universidad de Las Palmas de Gran Canaria, 2007, pág.344. Esta Tesis dedica dos Capítulos, el IV y el V, a "La iniciativa legislativa del ciudadano ante el Parlamento español" y a "La iniciativa legislativa ciudadana española en la práctica"; sin embargo no desarrolla una propuesta de modificación de las legislaciones autonómicas sobre la iniciativa legislativa que posibilite la operatividad de esta institución.

8 Las referencias a la legislación de la Comunidad Autónoma de Cataluña son de su Ley de 1995. La Ley catalana 1/2006, de la Iniciativa Legislativa Popular, se explica en páginas posteriores. 
Comunidad Autónoma representa un porcentaje de su censo electoral ${ }^{9}$ que oscilaría entre 0,57 de Galicia y el 2,51 de La Rioja. En el caso de Extremadura este porcentaje viene establecido en su Estatuto de Autonomía y es del 5 por 100 (art. 3 de la Ley 7/1985).

Las materias excluidas de la iniciativa popular por la práctica totalidad de las Comunidades Autónomas en sus leyes son: a) Las que se refieren a su organización territorial; b) Las que no sean de competencia exclusiva autonómica; c) Las de naturaleza presupuestaria y tributaria; d) Las referidas a la planificación general de la Comunidad Autónoma; y e) Las que se refieren a su organización institucional. Sin ánimo de ser exhaustivos, podemos citar otras materias excluidas expresamente de la iniciativa popular en algunas Comunidades, como serían: los derechos fundamentales y las libertades públicas (Leyes de Asturias y de Cantabria); el régimen electoral (Leyes de Canarias, Islas Baleares, La Rioja y el País Vasco); o la reforma del Estatuto de Autonomía (Leyes de Aragón, Canarias, Comunidad Valenciana, La Rioja y el País Vasco).

Las legislaciones autonómicas reproducen, en términos generales, las causas de inadmisión de una proposición de ley de iniciativa ciudadana previstas por la LO 3/1984 en su artículo 5. Estas causas, que han sido modificadas posteriormente, eran: 1) Que tenga por objeto alguna de las materias excluidas de la iniciativa popular previstas en la respectiva Ley autonómica; 2) Que no se hayan cumplimentado los requisitos exigidos en la presentación de la proposición de Ley. No obstante, si se tratase de defecto subsanable, la Mesa de la Asamblea legislativa respectiva lo comunicara a la Comisión Promotora para que proceda, en su caso, a la subsanación en el plazo de un mes; 3) El hecho de que el texto de la proposición verse sobre materias diversas carentes de homogeneidad entre si; 4) La previa existencia en la Asamblea legislativa de un proyecto o proposición de ley que verse sobre el mismo objeto de la iniciativa popular y que esté, cuando ésta se presenta, en el trámite de enmiendas u otro más avanzado; 5) El hecho de que sea reproducción de otra iniciativa popular de contenido igual o substancialmente equivalente, presentada durante la legislatura en curso; y 6) La previa existencia de una proposición no de ley aprobada por una Cámara que verse sobre la materia objeto de la iniciativa popular.

Admitida a trámite la referida proposición de ley por las Mesas de las Asambleas legislativas de las Comunidades Autónomas, y tras la notificación a la Comisión Promotora, se inicia el procedimiento de recogida de firmas que tendrá que hacerse en un plazo determinado. La extensión de la campaña de recogida de firmas varía de unas Comunidades Autónomas a otras. Así, en las Comunidades de Asturias, Canarias, Cantabria, Castilla La Mancha, Cataluña, Islas Canarias, La Rioja y Madrid el plazo es de tres meses. En las de Andalucía, Comunidad Valenciana, Galicia y el País Vasco es de cuatro meses. Por último, las Comunidades de Aragón, Castilla y León, Extremadura, Murcia y Navarra

9 Fuente: Censo Electoral de las Elecciones a Cortes Generales 2008, INE (www.ine.es). 
establecen un plazo de seis meses. Plazo que en algunas legislaciones autonómicas admiten prórroga y en otras resulta improrrogable.

De la tramitación parlamentaria interesa destacar que en la mayoría de Comunidades Autónomas el debate parlamentario se iniciará mediante la lectura de la memoria explicativa de las razones que aconsejan la tramitación y aprobación de la proposición de ley, presentada por la Comisión Promotora al inicio de procedimiento. Sólo las Comunidades de Aragón, Canarias, Galicia y las Islas Baleares contemplaban la posibilidad de que la Comisión Promotora interveniera en defensa de la proposición de ley a lo largo de la tramitación parlamentaria.

\section{BALANCE DE LA INSTITUCIÓN DE LA INICIATIVA POPULAR}

A nivel estatal se han presentado hasta la fecha 50 proposiciones de ley de iniciativa ciudadana, de las cuáles ninguna ha sido adoptada como ley ${ }^{10}$. Víctor Cuesta en su Tesis indica que una de ellas sí se ha adoptado como ley. Se esta refiriendo a la Proposición de Ley sobre reclamación de deudas comunitarias, presentada el 24 de noviembre de 1995. Esta Proposición fue, en realidad, subsumida en otra iniciativa (la Proposición de Ley de reforma de la Ley 49/1960, de 21 de julio, sobre Propiedad Horizontal), que daría lugar a Ley 8/1999, de 6 de abril, de Reforma de la Ley 49/1960, de 21 de julio, sobre Propiedad Horizontal.

A nivel autonómico, de acuerdo con Cuesta, hasta el 30 de abril de 2007 se habían presentado un total de 127 iniciativas legislativas populares. De las 17 Comunidades Autónomas, centraremos nuestra atención en Canarias, al ser la Autonomía en la que más iniciativas legislativas populares se han presentado; en Cataluña, al haber reformado su Ley de iniciativa legislativa popular; y en la Comunidad Valenciana, que se situaría en la media autonómica por el número de iniciativas populares.

La Comunidad Autónoma de Canarias tiene el honor de ser, como ya se ha comentado, la Comunidad en la que más iniciativas legislativas populares se han presentado, 27 iniciativas hasta la fecha ${ }^{11}$. Además, es importante des-

10 De acuerdo con la base de datos de la web del Congreso de los Diputados, de las 50 iniciativas legislativas populares presentadas, 19 caducaron, 15 fueron inadmitidas en términos absolutos, 8 fueron rechazadas, 1 fue retirada, 1 decayó, y 1 se subsumió en otra iniciativa. Actualmente continúan su tramitación 5 iniciativas legislativas populares.

11 Iniciativas legislativas populares presentadas en la Comunidad Autónoma de Canarias: Proposición de Ley viviendas para Canarias (presentación: 26/02/1987; aprobación Ley: 13/07/1989); Proposición de Ley de Reorganización Universitaria de Canarias —3 proposiciones refundidas- (presentación: 17/06/1988; aprobación Ley: 26/04/1989); Proposición de Ley de Reordenación de Enseñanzas Universitarias de Canarias (presentación: 27/10/1988; inadmisión); Proposición de Ley sobre retribuciones del funcionario docente no universitario (presentación: 09/01/1990; inadmisión); Proposición de Ley para la declaración del Rincón como paisaje protegido (presentación: 09/01/1990; aprobación Ley: 15/07/1992); Proposición de Ley sobre protección de los animales (presentación: 12/06/1990; no supera toma en consideración); Proposición de Ley de referéndum sobre las relaciones de Canarias con las Comunidades Europeas (presen- 
tacar que 6 de dichas iniciativas han sido aprobadas como Ley (11 no fueron admitidas a trámite; 3 caducaron; 4 fueron rechazadas en la toma en consideración; y 3 continúan actualmente tramitándose).

El canario Víctor Cuesta ${ }^{12}$ se pregunta por qué en su Comunidad se han presentado un número tan elevado de iniciativas, en comparación con las restantes Comunidades (a una distancia considerable le seguiría Galicia con 15 iniciativas). Apunta que, tanto en Canarias como en Galicia, la cantidad de firmas requeridas representa un porcentaje de electores sensiblemente inferior a la media. La menor proporción de firmas requeridas puede, indudablemente, incentivar la presentación de iniciativas, pero por sí solo no explicaría el caso canario. Otras posibles causas que estimularían esta participación ciudadana, según Cuesta, serían: a) Que en Canarias, al igual que en Galicia (y, tras la reforma de 2006, en Cataluña), la Comisión Promotora, cuenta con la posibilidad de defender la iniciativa popular ante el Pleno de la Cámara; y b) Que Canarias, Galicia y Cataluña concentran la mayor parte de las iniciativas legislativas populares autonómicas aprobadas.

tación: 12/03/1990; inadmisión); Proposición de Ley reguladora de la condición de residente (presentación: 18/12/1991; inadmisión); Proposición de Ley reguladora del Consejo de la Juventud de Canarias (presentación: 09/05/1994; caducidad); Proposición de Ley para la declaración del Barranco de Veneguera como Espacio Natural Protegido (presentación: 14/09/1995; aprobación Ley: 15/04/1998); Proposición de Ley para la creación de un Hospital público en la zona sur y suroeste de la isla de Tenerife (presentación: 28/04/1998; aprobación Ley: 05/07/2000); Proposición de Ley creación de un servicio de transporte público de tracción eléctrica para la zona norte de la isla de Tenerife (presentación: 29/12/1998; no supera toma en consideración: 13/06/2001); Proposición de Ley de Responsabilidad Política del Parlamento de Canarias (presentación: 11/01/1999; inadmisión: 12/04/1999); Proposición de Ley de modificación de la Ley de Coordinación de Policías Locales de Canarias (presentación: 08/07/1999 ; caducidad: 12/04/2000); Proposición de Ley para modificar la Ley 6/1997, de Coordinación de Policías Locales de Canarias (presentación: 14/09/1999: caducidad: 12/04/2000); Proposición de Ley de Acceso a la Función Pública Canaria del profesorado interino, sustituto y contratado (presentación: 07/10/1999; inadmisión: 12/01/2000); Proposición de Ley Reguladora de la residencia canaria (presentación: 01/02/2001; inadmisión: 13/02/2001); Proposición de Ley declarando reserva natural especial la totalidad del malpaís de Güímar y el camino de El Socorro (presentación: 13/06/2001; aprobación Ley: 26/12/2006); Proposición de Ley sobre profesorado interino, sustituto y contratado (presentación: 25/02/2003; inadmisión: 05/05/2003); Proposición de Ley de declaración de la Reserva Natural Especial del Litoral Noreste de Granadilla (presentación: 29/08/2003; no supera toma en consideración: 12/01/2005); Proposición de Ley reguladora de las listas de espera en la Sanidad Pública Canaria (presentación: 23/10/2003; inadmisión 19/04/2005); Proposición de Ley de Capitalidad. (presentación: 21/12/2005; no supera toma en consideración:11/12/2006); Proposición de Ley solicitando la descentralización del voto para las próximas elecciones a las Cámaras de Comercio, Industria y Navegación, 2006 (presentación: 04/01/2006; inadmisión: 07/07/2006); Proposición de Ley sobre residencia y permisos de trabajo en el ámbito de la Comunidad Autónoma de Canarias (presentación: 24/10/2006; inadmisión: 02/01/2007); Proposición de Ley reguladora de la ubicación de las infraestructuras de radiocomunicación y telefonía móvil de Canarias (presentación: 06/11/2006; tramitándose); Proposición de Ley por la que se establece y regula una red de apoyo a la mujer embarazada (presentación: 30/03/2007; tramitándose); Proposición de Ley de medidas para la renovación de la planta alojativa turística y la contención de su crecimiento (presentación: 09/10/2007; no supera toma en consideración, 23/12/2008). FUENTE: Parlamento de Canarias www.parcan.es/iniciativas/index.py

12 CUESTA. Op. cit., págs. 423 y 424. 
Ninguna de estas causas explicaría el elevado número de iniciativas presentadas en Canarias. A expensas de un estudio sociológico al respecto, considero que el hecho insular es un elemento a tener en cuenta.

En Cataluña, hasta el día de hoy, se han presentado un total de 16 iniciativas $^{13}$. Si observamos las fechas de las iniciativas legislativas populares presentadas en esta Comunidad Autónoma, podemos comprobar como durante la vigencia de la Ley 2/1995 únicamente se presentaron 6 iniciativas (3 de ellas fueron finalmente aprobadas). Las 10 iniciativas restantes se presentaron estando ya en vigor la nueva normativa, la Ley 1/2006. Esta progresión tan importante en el número de iniciativas legislativas populares presentadas es una prueba evidente, en mi opinión, de la eficacia de la reforma, potenciando la participación ciudadana en el ámbito legislativo.

En la Comunidad Valenciana se han presentado hasta el momento un total de 7 iniciativa legislativas populares ${ }^{14}$. Las pocas iniciativas legislativas

13 Iniciativas legislativas populares presentadas en la Comunidad Autónoma de Cataluña: Proposición de Ley para la aprobación de la convocatoria de un referéndum de autodeterminación (inadmisión 16/06/2009); Proposición de Ley Electoral de Cataluña (admisión a trámite 17/02/2009), Proposición de Ley de modificación del artículo 6 del Texto Refundido del Ley de Protección de los Animales, aprobado mediante Decreto Legislativo 2/2008 (presentación 29/10/2008; admisión a trámite: 11/11/2008); Proposición de Ley reguladora de la soberanía nacional (presentación: 04/03/2008; inadmisión: 13/03/2008); Proposición de Ley para la prohibición del cultivo de productos agrícolas modificados genéticamente (presentación: 01/02/2008; publicación de prórroga de plazo para presentar firmas: 07/07/2008); Proposición de Ley por la cual se aprueba el Proyecto de constitución de Cataluña (presentación: 14/01/2008; inadmisión: 17/01/2008); Proposición de Ley por la cual se establece y regula una red de apoyo a la mujer embarazada (presentación: 28/01/2007; publicación prórroga de plazo para presentar firmas: 20/04/2008); Proposición de Ley de medidas urgentes para la vivienda (presentación: 27/03/2007; tramitándose actualmente); Proposición de Ley para la atención de la fibromiálgia y el síndrome de fatiga crónica a Cataluña (presentación: 05/03/2007; retirada de a iniciativa en el Pleno: 21/05/2008); Proposición de Ley de la enseñanza en la lengua materna y el bilingüismo escolar (presentación: 04/04/2006; devolución iniciativa: 19/12/2007); Proposición de Ley de medidas de fomento de la vivienda protegida (presentación: 21/02/2003; caducidad por inactividad del interesado: 23/09/2003); Proposición de Ley sobre la educación infantil de cero a tres años (presentación: 05/03/2002; aprobación en el Pleno: 30/06/2004). Se convirtió en la Ley 5/2004, de 9 de julio, de creación de hogares infantiles de calidad; Proposición de Ley de desarrollo del artículo 4 de la Ley 15/84 sobre el Juego a Cataluña (presentación: 20/11/1998; caducidad por inactividad del interesado: 21/16/1998); Proposición de Ley de apoyo a las selecciones catalanas (presentación: 18/11/998; aprobación en el Pleno: 28/07/1999). Se convirtió en la Ley 9/1999, de 30 de julio, de apoyo a las selecciones catalanas; Proposición de Ley de creación del servicio psiquiátrico catalán de urgencias a domicilio (presentación: 20/11/1996; inadmisión: 04/02/1997); Proposición de Ley sobre la prohibición de la incineración de los residuos (presentación: 24/03/1998; aprobación en el Pleno: 25/10/2000). Se convirtió en la Ley 11/2000, de 13 de noviembre, reguladora de la incineración de residuos. Fuente: Parlamento de Cataluña.

14 Iniciativas legislativas populares presentadas en la Comunidad Valenciana: Proposición de Ley por la que se establece y regula una red de apoyo a la mujer embarazada (admisión a trámite: 15/04/2008; aprobada como Ley 6/2009, de 30 de junio, de protección a la maternidad, tras enmienda a la totalidad con texto alternativo); Proposición de Ley de compensación cheque bebé de la Comunitat Valenciana (admisión a trámite: 04/04/2008); Proposición de Ley de modificación del aparatado 1.b del art. 20 de la Ley 8/1986, de 29 de diciembre de la Generalitat, de ordenación del comercio y superficies comerciales (admisión a trámite: 02/05/2006; declaración 
populares presentadas en la Comunidad Valenciana no han cumplido su objetivo: su adopción y aprobación como Ley por las Cortes Valencianas. Recientemente, ha sido aprobada la Ley 6/2009, de 30 de junio, de protección a la maternidad. Dicha Ley tiene su origen en una iniciativa popular, la Proposición de Ley por la que se establece y regula una red de apoyo a la mujer embarazada, admitida a trámite el 20 febrero de 2008. Sin embargo, esta Proposición se desvirtuó como tal al aprobarse una enmienda a la totalidad con texto alternativo presentada por el Grupo Parlamentario Popular, que finalmente sería aprobado.

La Comunidad Valenciana sólo supera en número de iniciativas presentadas a las Comunidades Autónomas de: Cantabria, Castilla y León, CastillaLa Macha, Extremadura, La Rioja y Madrid. Este evidente fracaso de la participación ciudadana a través de esta institución de democracia semidirecta debe ser objeto de análisis.

\section{LA REFORMA DE LA LO 3/1984, REGULADORA DE LA INICIATIVA LEGISLATIVA POPULAR, Y LA NUEVA LEY CATALANA 1/2006, DE LA INICIATIVA LEGISLATIVA POPULAR. LAS RESTRICCIONES DE LAS LEGISLACIONES AUTONÓMICAS}

La normativa autonómica sobre la iniciativa popular ha demostrado ser muy restrictiva. Por ello, cuando en los últimos años, especialmente en el ámbito local y, en menor medida, en el autonómico, se ha impulsado la democracia participativa, se ha procedido a modificar las leyes relativas a la iniciativa legislativa popular, eliminando o disminuyendo las limitaciones que han impedido el desarrollo real de la participación ciudadana en el ámbito legislativo.

A nivel estatal, la LO 3/1984, reguladora de la Iniciativa Legislativa Popular, ha sido reformada por la LO 4/2006, de 26 de mayo. A nivel autonómico, únicamente $^{15}$, hasta el momento, la Comunidad Autónoma de Cataluña ha aprobado una nueva Ley, la Ley 1/2006, de 16 de febrero, de la Iniciativa Legislativa Popular, que deroga la ley anterior de 1995.

El Preámbulo de la LO 4/2006 señala que "El tiempo transcurrido y la experiencia acumulada desde la aprobación de la Ley Orgánica 3/1984, de

de caducidad: 19/12/2006); Proposición de Ley de la Academia de la Lengua Valenciana, en modificación de la Ley de creación de la Academia Valenciana de la Lengua (no admisión: 03/05/05); Proposición de Ley de los derechos de la familia (admisión a trámite: 12/05/2001; declaración de caducidad: 07/05/2002); Proposición de Ley de la Academia del Idioma Valenciano, en modificación de la Ley de la Academia Valenciana de la Lengua (no admisión: 06/03/2001); Proposición de Ley reguladora del proceso de ordenación y protección de la huerta de Valencia como espacio natural protegido (admisión a trámite: 06/02/2001; no tomada en consideración: 15/11/2001).Fuente: Boletín Oficial de las Cortes Valencianas.

15 La Comunidad de Murcia modificó por Ley 7/2006, su Ley de ILP de 1984. Sin embargo, su único artículo se limita a actualizar la cuantía por resarcimiento de gastos de la Comisión Promotora de una iniciativa legislativa popular. No estamos, en presencia, por tanto, de una reforma de la Ley $7 / 2006$. 
26 de marzo, hacen aconsejables algunas adecuaciones de la institución de participación popular para evitar requisitos innecesarios e incorporar mejoras que faciliten su ejercicio". Las modificaciones más significativas introducidas con esta reforma son:

- Simplificación de los requisitos del escrito de presentación. El mismo ya no debe contener "Un documento en el que se detallen las razones que aconsejan, a juicio de los firmantes, la tramitación y aprobación por las Cámaras de la proposición de ley" (letra b — suprimida- del art. 3.2).

- Supresión de alguna causa de inadmisión. Se suprime como causa de inadmisión de la proposición "La previa existencia de una proposición no de ley aprobada por una Cámara que verse sobre la materia objeto de la iniciativa popular, (letra $\mathrm{f}$-suprimida- del art. 5.2).

- Ampliación del plazo de recogida de firmas. Se amplía a nueve meses (antes eran seis), prorrogable por otros tres cuando concurra causa mayor apreciada por la Mesa del Congreso.

- Previsión de la firma electrónica.

- Intervención de la Comisión Promotora durante la tramitación parlamentaria. Se establece que los Reglamentos de las Cámaras puedan contemplar la participación de una persona designada por la Comisión Promotora (art. 13.2).

- Actualización del importe de la compensación estatal por los gastos realizados. Se pasa de 30 millones de pesetas a 300.000 euros.

Tras la reforma de la LO 3/1984, operada por la LO 4/2006, se han presentado hasta el momento 11 iniciativas legislativas populares ( 4 en el año 2006, 2 en el 2007, 1 en el 2008, y 4 en el 2009). Pese al poco tiempo transcurrido desde la entrada en vigor de la referida reforma, ya parece apreciarse un aumento en el número de las iniciativas. De todos modos, todavía resulta un tanto prematuro evaluar el impacto de la reforma.

En Cataluña, el preámbulo de la Ley 1/2006 señala, con relación a la anterior Ley 2/1995, que "la voluntad de acercar más la acción pública a los ciudadanos no queda suficientemente reflejada en dicha Ley, razón por la que es precisa su puesta al dia, mejora y modificación formulando una nueva Ley". Para ello, continúa diciéndonos el Preámbulo, "Se han tenido en cuenta la experiencia acumulada durante la vigencia de la Ley 2/1995, los procesos de debate ciudadano sobre esta figura, promovidos por el Gobierno, $y$ las consultas a algunas entidades impulsoras, que han realizado aportaciones que deben permitir una mejora legislativa sustancial.. Con relación a la tramitación parlamentaria de las iniciativas legislativas populares, deben tenerse también presente las modificaciones introducidas por el nuevo Reglamento del Parlamento de Cataluña, de 22 de diciembre de 2005.

Las modificaciones más significativas incorporadas en la Ley 1/2006 son las siguientes ${ }^{16}$.

16 Cfr. Monográfico «La Llei 1/2006, de 16 de febrer de la iniciativa legislativa popular, una eina per a la participación, en El Pas, Núm. 20, Diputació de Barcelona, 2007. 
Para facilitar su utilización: - Reducción del número de firmas necesarias: Se ha pasado de 65.000 a 50.000 firmas; -Ampliación de la legitimidad para respaldar una iniciativa legislativa popular a personas mayores de dieciséis años; -Extensión de la legitimidad para promover y/o respaldar una iniciativa popular a personas nacionales de otros países con residencia legal en Cataluña; -Ampliación del plazo para recoger firmas: De 90 a 120 días prorrogables por causas justificadas en 60 días más; —Posibilidad de atender consultas y recibir asesoramiento técnico por parte de los servicios del Parlamento de Cataluña para resolver las dudas que puedan tener los las personas promotoras, ayudándoles también en el cumplimiento de los requisitos formales; - Posibilidad de otorgar el Parlamento un anticipo no superior a 3.000 euros para cubrir los primeros gastos de la recogida de firmas a petición de la Comisión Promotora; - Previsión de la firma electrónica.

Para visualizar la relación entre la ciudadanía y el Parlamento (remisión de la Ley 1/2006 al Reglamento del Parlamento de Cataluña). —Una persona en representación de la Comisión Promotora presenta al Pleno del Parlamento la proposición de ley para iniciar el debate de totalidad (art. 105.2 del Reglamento); - Si la proposición de ley no es rechazada en el debate de totalidad y continúa su tramitación, una persona en representación de la Comisión Promotora puede presentar en el debate final en el Pleno la proposición definitiva del texto de la Comisión Parlamentaria que se ha de someter a votación (art. 112.1 del Reglamento).

Para facilitar el seguimiento del trámite parlamentario (remisión de la Ley 1/2006 al Reglamento del Parlamento de Cataluña), —La Comisión Promotora puede hacer llegar a la Mesa del Parlamento propuestas o quejas relativas a la tramitación de la iniciativa. La Mesa, una vez oída la Junta de Portavoces, debe responder a la comisión en el plazo de quince días a partir de la recepción de dichas propuestas o quejas. - La Comisión Promotora debe ser notificada del Dictamen de la Comisión Legislativa que se presentará al Pleno para su votación final (art. 110.3 del Reglamento).

Para garantizar la titularidad de la iniciativa. La Comisión Promotora, antes de iniciarse las votaciones en el Pleno o en la comisión, si ésta actúa en sede legislativa plena, puede solicitar la retirada de la proposición de ley (art. 116 del Reglamento del Parlamento de Cataluña).

La reforma de las Leyes de Iniciativa Popular se vuelve imprescindible si queremos que esta institución de participación ciudadana funcione, aumentando significativamente el número de proposiciones de ley y que éstas, tras su tramitación parlamentaria, se conviertan en leyes. La doctrina no duda en señalar la actual inoperatividad de esta institución, dadas las limitaciones formales, materiales y procedimentales. En este sentido, Astarloa, con relación a la Iniciativa Legislativa Popular a nivel estatal, señala que no es una figura que haya arraigado en nuestro país, siendo los motivos, según este autor, diversos: desde el desinterés generalizado por la cosa pública hasta las propias trabas de procedimiento, así como la necesidad de reunir un número 
muy notable de firmas ${ }^{17}$. Eliseo Aja y María Jesús Larios, por su parte, tras recordarnos que el legislador autonómico no ha sido menos restrictivo en su regulación, sostienen que la "normativa relativa a las materias excluidas, la obligación de someter las iniciativas al trámite de la toma en consideración, la imposibilidad en la mayoría de las ocasiones de que los promotores participen en el desarrollo de la tramitación parlamentaria de la ley, incluso los plazos y las indemnizaciones incentivan poco la utilización de estas vías " ${ }^{18}$.

Dado la gran semejanza de las legislaciones autonómicas en esta materia, pasamos a continuación a examinar los requisitos, tanto materiales como formales, que exige la Ley 5/1993, reguladora de la Iniciativa Legislativa Popular de la Comunidad Valenciana, comparándolos con los que se exigen en Cataluña, tras la reforma de 2006.

* El art. 2 prescribe que "La iniciativa legislativa popular se ejerce mediante la presentación de proposiciones de ley suscritas como minimo por las firmas de 50.000 electores, autenticadas en la forma que determina esta ley". De acuerdo con el censo electoral de la Comunidad Valenciana, este número de firmas representaría el 1,43\% de los electores valencianos (3.503.961). Porcentaje de electores muy elevado si lo comparamos con el de las otras Comunidades Autónomas. Solamente las Comunidades de Aragón, Cantabria, Extremadura, La Rioja, País Vasco y Navarra superarían este porcentaje.

Por su parte, la Comunidad de Cataluña, tras la reforma de 2006, redujo el número de firmas necesarias, pasado de 65.000 a 50.000. Se exige, por tanto, igual número de firmas que en la Comunidad Valenciana, pero debemos tener en cuenta que el número de electores es muy superior en aquella Comunidad (5.324.578). Además, debemos recordar que en Cataluña se ha extendido la legitimidad para respaldar una iniciativa popular a personas mayores de dieciséis años y a personas nacionales de otros países con residencia legal en dicha Comunidad.

Dos de las iniciativas legislativas populares presentadas en la Comunidad Valenciana han sido declaradas caducadas al haber transcurrido el plazo concedido a la Comisión Promotora para la recogida de firmas, a) Sin que se hubieran entregado las mismas ante la Junta Electoral de la Comunidad Valenciana (BOCV 153, de 27 de mayo de 2002). Proposición de Ley de los derechos de la familia (admisión a trámite: 12/05/2001; declaración de caducidad: 07/05/2002). b) Efectuado el recuento de firmas en acto público el 15 de diciembre de 2006, no se había superado el requisito mínimo de las 50.000 firmas necesarias (BOCV 248, de 29 de diciembre de 006). Proposición de Ley de modificación del aparatado 1.b del art. 20 de la Ley 8/1986, de 29 de diciembre de la Generalitat, de ordenación del comercio y superficies comerciales (admisión a trámite: 02/05/2006; declaración de caducidad: 19/12/2006).

17 ASTARLOA. Op. cit., pág. 314.

18 AJA FERNÁNDEZ, E., LARIOS PATERNA, M., "Parlamentos autonómicos y participación popular. La participación de los grupos sociales en la elaboración parlamentaria de las leyes", Corts Anuario de Derecho Parlamentario, n. ${ }^{\circ}$ 6, Extraordinario, 1998, pág. 83. 
Actualmente, se encuentran en fase de recogida de firmas dos iniciativas, habiendo solicitado la Comisión Promotora de una de ellas que el mes de agosto fuera declarado inhábil, dada la dificultad en conseguir las 50.000 firmas. La Mesa de las Cortes Valencianas, en fecha 10 de junio de 2008, ha declarado inhábil el mes de agosto del presente año a los efectos del cómputo de los cuatro meses para la recogida de firmas (BOCV 81, de 30 de junio de 2008).

Por tanto, es evidente que con el actual número de firmas requeridas por la Ley 5/1993 no se facilita la participación ciudadana.

* El art. 3, relativo a las Materias excluidas de la iniciativa legislativa popular, señala las siguientes materias: Aquellas que hagan referencia al título I del Estatuto de Autonomía de la Comunidad Valenciana y a la organización territorial de la misma. Las que afecten a la organización institucional de la Generalidad, prevista en el título II del Estatuto de Autonomía. Las de naturaleza tributaria y presupuestaria. Las referidas a la planificación general de la actividad económica de la Comunidad. Todas aquellas cuya competencia legislativa no corresponda a las Cortes Valencianas, o supongan una reforma del Estatuto de Autonomía.

La Ley catalana establece que no podrán ser objeto de iniciativa legislativa popular "las materias que el Estatuto de autonomía reserva a la iniciativa legislativa exclusiva de los diputados, los grupos parlamentarios o el Gobierno, de los presupuestos de la Generalidad y de las materias tributarias" (art. 1). También, al igual que el art. 3.5 de la Ley valenciana, no admite proposiciones de ley que tengan por objeto alguna materia sobre la cual la Generalidad no tiene atribuida la competencia (art. 6.2.a).

Como antes veíamos, las Cortes Valencianas no han admitido a trámite, hasta el momento, dos iniciativas legislativas populares relativas ambas a cuestiones idiomáticas. Materia que quedaría excluida de esta institución, de acuerdo con el art. 3.1 de la Ley 5/1993, al estar regulada la cuestión en el Título I del Estatuto de Autonomía de la Comunidad Valenciana. Proposición de Ley de la Academia del Idioma Valenciano, en modificación de la Ley de la Academia Valenciana de la Lengua (no admisión: 06/03/2001). Proposición de Ley de la Academia de la Lengua Valenciana, en modificación de la Ley de creación de la Academia Valenciana de la Lengua (no admisión: 03/05/05).

"En lo referente a las causas de inadmisibilidad que, de conformidad con lo dispuesto el artículo 7.2 a) debe examinar la Mesa de las Cortes Valencianas, en el trámite de admisión de la iniciativa, se aprecia que la iniciativa legislativa popular promovida incurre en el supuesto establecido en el artículo 3, apartado 1, que establece textualmente como materias excluidas de la iniciativa legislativa popular, en su apartado primero "Aquéllas que hagan referencia al Título I del Estatuto de Autonomía de la Comunidad Valenciana y a la organización territorial de la misma". En el contenido el Título I del Estatuto de Autonomía de la Comunidad Valenciana, está incluido el artículo 7 donde se establece que: 
"1. Los dos idiomas oficiales de la Comunidad Autónoma son el valenciano y el castellano. Todos tienen derecho a conocerlos y usarlos.

2. La Generalitat Valenciana garantizará el uso normal y oficial de las dos lenguas y adoptará las medidas necesarias para asegurar su conocimiento.

3. Nadie podrá ser discriminado por razón de su lengua.

4. Se otorgará especial protección y respeto a la recuperación del valenciano.

5. La ley establecerá los criterios de aplicación de la lengua propia en la Administración y en la enseñanza.

6. Mediante ley se delimitarán los territorios en los que predomine el uso de una y otra lengua, así como los que puedan exceptuarse de la enseñanza y del uso de la lengua propia de la Comunidad".

La Mesa de las Cortes Valencianas considera que el texto de la iniciativa legislativa popular hace "referencia" a lo establecido en el artículo 7 EACV, integrado dentro del Título I del mismo, no procediendo, de acuerdo con el artículo 3 y 7.2 a) de la Ley 5/1993, su admisión a trámite." (Boletín Oficial de las Cortes Valencianas, números 92 y105, de 2 de abril de 2001 y de 23 de mayo de 2005 y respectivamente).

* El artículo 5, relativo a la Iniciación del procedimiento, prescribe que el mismo "se iniciará con la presentación ante la Mesa de las Cortes Valencianas, a través del registro de entrada, de un escrito que contendrá: a) El texto articulado de la proposición de ley, precedido de una exposición de motivos. b) Una memoria con una exposición detallada de las razones que aconsejan, según los firmantes, que las Cortes Valencianas tramiten y aprueben la proposición de ley. 2. El escrito de presentación de la proposición de ley estará firmado como minimo por diez ciudadanos que gocen de la condición y derechos contemplados en el artículo 1 y no incurran en ninguna de las causas de inelegibilidad o incompatibilidad que señala la Ley Electoral Valenciana para los Diputados. En dicho escrito se designará, de entre sus firmantes, y por los mismos, una comisión promotora que estará constituida por un mínimo de tres y un máximo de cinco personas."

También en el artículo 5 de la Ley catalana de la Iniciativa Legislativa Populr se relacionan los documentos que deben acompañar a la solicitud de admisión de la iniciativa. Estos documentos son: a) El texto articulado de la proposición de ley, precedido de una exposición de motivos; b) Una memoria explicativa de las razones que aconsejan, según el parecer de las personas firmantes, la tramitación y aprobación de la proposición de ley por el Parlamento; y c) La relación de los miembros que componen la comisión promotora y de sus datos personales.

La Ley valenciana y la catalana exigen, como vemos, una memoria explicativa de las razones que aconsejan la tramitación y aprobación de la proposición de ley. Sin embargo, a nivel estatal, tras la reforma operada por la LO 4/2006, se ha suprimido esta memoria. Lógica supresión si tenemos en cuenta que se prevé la intervención de la Comisión Promotora durante la tramita- 
ción parlamentaria y que, en todo caso, ya existe una exposición de motivos en el texto articulado que se presenta. Por ello, al contemplar también la nueva Ley catalana que regula la iniciativa legislativa popular, debería haberse suprimido este requisito.

* Son causas de inadmisibilidad de una proposición de ley de la ILP, según el art. 7 de la Ley 5/1993, las siguientes: a) Que tenga por objeto alguna de las materias citadas en el artículo 3 de esta ley. b) Que falte alguno de los requisitos del artículo 5 de esta ley. No obstante, si se tratara de un defecto reparable, la Mesa de las Cortes Valencianas lo notificará a la comisión promotora para que lo subsane en el plazo de un mes. c) Que exista previamente en las Cortes Valencianas un proyecto o proposición de ley que verse sobre la misma materia objeto de la iniciativa legislativa popular. Si la proposición de iniciativa popular entrará en las Cortes Valencianas con anterioridad a la finalización del plazo reglamentario de presentación de enmiendas a la iniciativa parlamentaria en trámite, se admitirá como enmienda de la ley de que se trate, de acuerdo con lo previsto en los articulos $107 \mathrm{y}$ siguientes del Reglamento de las Cortes Valencianas. d) Que el texto regule materias diversas sin que tengan la necesaria bomogeneidad entre ellas. e) Que reproduzca otra iniciativa legislativa popular de idéntico o equivalente contenido, presentada durante la misma legislatura.

En la legislación catalana encontramos las mismas causas de inadmisibilidad excepto las descritas en las letras c y d del art. 7 de la Ley valenciana. Con relación a la causa de la letra c, la Ley catalana señala: "La Mesa, si el Parlamento está tramitando algún proyecto o proposición de ley sobre las mismas materias de que trata la proposición de ley de la iniciativa legislativa popular, debe comunicarlo a la comisión promotora para que decida, en el plazo de quince dias hábiles, si mantiene la propuesta o la retira. En el supuesto de que la comisión promotora opte por mantener la propuesta, la Mesa debe acordar que las iniciativas legislativas se acumulen y se tramiten conjuntamente y debe comunicarlo a la comisión promotora." (art. 6.3). Esta solución es, a mi entender, más respetuosa con la voluntad ciudadana, dando protagonismo en la decisión final a la Comisión Promotora.

* La tramitación parlamentaria se regula en los artículos 17, 18 y 19.

El art. 17, con relación a la Normativa aplicable, nos dice que "La tramitación parlamentaria de las proposiciones de ley de iniciativa legislativa popular se regirá por lo dispuesto en el Reglamento de las Cortes Valencianas, sin perjuicio de las especialidades que se deriven de este título y de esta ley."

El nuevo Reglamento de las Cortes Valencianas, aprobado por el Pleno de las Cortes en 2006, sólo dedica a la tramitación parlamentaria de la proposición de ley un artículo, el 126, que reza así:

«1. Las proposiciones de ley de iniciativa legislativa popular podrán ser ejercidas atendiendo a lo preceptuado en la Ley 5/1993, de 27 de diciembre, reguladora de la iniciativa legislativa popular de la Comunitat Valenciana. 2. Las proposiciones de ley de iniciativa popular serán examinadas por la Mesa de Les Corts a efectos de verificar el cumplimiento de los requisitos 
legalmente establecidos. Si los cumplen, su tramitación se ajustará a lo previsto en el artículo anterior para las proposiciones de ley, retomando dicho procedimiento desde su toma en consideración y exceptuando el trámite de presentación al Pleno al no existir posibilidad reglamentaria de comparecencia de los proponentes."

El precepto se limita a indicar que dichas proposiciones de ley se tramitarán de forma idéntica a las demás proposiciones de ley. Remarcando, eso sí, que no existe "posibilidad reglamentaria de comparecencia de los proponentes".

La Ley 1/2006 de la Comunidad Autónoma catalana remite para la tramitación parlamentaria, al igual que la Ley valenciana, a los preceptos del Reglamento del Parlamento catalán que regulan el procedimiento legislativo (art. 14).

A nuestros efectos, interesa destacar el art. 105.2 del Reglamento del Parlamento catalán, al señalar que el debate de totalidad se inicia, en el caso de una proposición de ley de iniciativa legislativa popular, con su presentación a cargo de un miembro de la Comisión Promotora. Presentación de la iniciativa popular en el Pleno que no es posible con la actual regulación valenciana y que, obviamente, no favorece a esta institución de democracia semidirecta.

Esta intervención de la Comisión Promotora no se limita al momento del debate de totalidad, dado que si la proposición de ley no es rechazada y continúa su tramitación, la comisión parlamentaria correspondiente "puede oír a las personas que representan a la comisión promotora" (art. 14.2 de la Ley 1/2006). Además, en cualquier momento, durante la tramitación parlamentaria, la comisión promotora puede hacer llegar a la Mesa del Parlamento propuestas o quejas relativas a la tramitación de la iniciativa (art. 14.3). Por último, el Reglamento del Parlamento catalán prevé que una persona en representación de la Comisión Promotora pueda presentar en el debate final en el Pleno la proposición definitiva del texto de la Comisión Parlamentaria, que se ha de someter a votación (art. 112.1).

Las legislaciones de las Comunidades Autónomas de Aragón, Canarias y las Islas Baleares también permiten la defensa de la proposición de ley, en el debate plenario de toma en consideración, por parte de un miembro de la Comisión Promotora. Galicia es más flexible, permitiendo que está defensa de la iniciativa popular la pueda realizar tanto uno de los miembros de la Comisión Promotora como uno de los firmantes de la misma, designado, eso sí por aquélla (art. 12 de la Ley gallega 1/1988).

También, a nivel nacional, tras la reforma operada por la LO 4/2006, se prevé que en la tramitación parlamentaria, efectuada conforme a lo que dispongan los Reglamentos de las Cámaras, la posible participación de una persona designada por la Comisión Promotora (art. 13.2 de la LO 3/84). Debería procederse a reformar los Reglamentos de las Cámaras pues, al día de hoy, no contemplan esta participación de la Comisión Promotora.

Estas intervenciones de la Comisión Promotora permiten visualizar la relación entre la ciudadanía y el Parlamento, favoreciendo la institución de la iniciativa legislativa popular y, por ende, la participación ciudadana. 
Como consecuencia de esta falta de intervención de algún miembro de la Comisión Promotora en el trámite parlamentario, el artículo 19 de la Ley valenciana de ILP, dedicado al Debate parlamentario, indica que "El debate se iniciará mediante la lectura de la documentación presentada por la comisión promotora a la cual se refiere el apartado 1, b), del articulo 5 de esta ley". El precepto se refiere a la memoria explicativa de las razones que aconsejarían la incitativa. Memoria que, recordémoslo, ya no se exige por la legislación estatal tras la reforma de la LO 3/84.

Tras este estudio de la Ley 5/1993, fácilmente se constata en la Comunidad Valenciana una separación absoluta, un distanciamiento, entre la sociedad y el Parlamento. Recordemos que la participación ciudadana tiene, precisamente, una fundamentación de carácter político o filosófico que justificaría su existencia, como nos comenta Fernando Pindado, por "la fractura que se va produciendo entre las personas elegidas democráticamente para gobernar y la ciudadanía que representan"19. La participación es, por tanto, una reacción a esa separación o divorcio

La falta de una colaboración estrecha entre la Comisión Promotora de una iniciativa popular y el Parlamento puede haber contribuido al fracaso de la operatividad de esta institución de democracia semidirecta ${ }^{20}$. Esta falta de colaboración es reflejo de la desconfianza en dicha institución por parte del poder político. En realidad, estamos en presencia de un problema de doble desconfianza ${ }^{21}$ entre la sociedad civil y poder político.

El poder político esgrime su legitimidad democrática alcanzada en las urnas. Precisamente este fue el criterio del Consell sobre la proposición de ley de modificación de la Ley 5/93, presentada por el Grupo Parlamentario Ezquerra Unida del País Valencià y admitida a trámite el 20 de noviembre de 2001.

«...no hay que olvidar que en un sistema político parlamentario, y concretamente en el ámbito de la Comunidad Valenciana, corresponde única y excluidamente a las Cortes Valencianas la potestad de aprobar las leyes según lo establecido en el artículo 10 del Estatuto de Autonomía, y ello porque la Cámara legislativa representa al pueblo valenciano. La legitimidad democrática de los miembros de las Cortes Valencianas está basada en el apoyo popular obtenido en las urnas, por ello, los Grupos Parlamentarios, que son reflejo de la voluntad popular y de las distintas sensibilidades de la sociedad valenciana, deben ostentar un papel pre-

19 PINDADO. Op. cit., pág. 22.

20 Colaboración que sí es visible en el caso de Cataluña desde el primer momento (vgr. en su legislación se determina - art. 5.2- que los servicios jurídicos del Parlamento han de asesorar a los miembros de la Comisión Promotora para facilitarles el cumplimiento de los requisitos formales).

21 El profesor Antonio Colomer nos explica, en diversos trabajos, el problema de la doble desconfianza en el ámbito municipal, entre la sociedad civil organizada en torno a asociaciones de vecinos y el poder local, y en las relaciones que establecen entre la ciudadanía y la Administración, entre administrados y funcionarios (Vid. COLOMER VIADEL, A., Constitución, Estado y Democracia en el siglo XXI, Editorial Universidad Politécnica de Valencia, 2006, págs. 207 y ss.). 
ponderante en cualquier procedimiento tendente a la aprobación de las leyes".

La Proposición de ley del Grupo Parlamentario Esquerra Unida del País Valencià fue presentada inmediatamente después de que la primera Proposición de Ley de iniciativa legislativa popular, reguladora del proceso de ordenación y protección de la huerta de Valencia como espacio natural protegido, no pasara el trámite de la toma en consideración. Una iniciativa que había recibido el respaldo de 117.674 ciudadanos con sus respectivas firmas.

La proposición de ley de modificación de la Ley 5/93 mejoraba, sin duda alguna, dicha norma. Se pretendía que la Comisión Promotora de una iniciativa legislativa popular pudiera designar a alguno de sus miembros para la defensa de la proposición en el trámite de toma en consideración ante el Pleno del Parlamento. También se quería modificar el artículo 4, relativo a la compensación a la Comisión Promotora por los gastos soportados, no sujetando esta compensación a cargo de la Generalitat Valenciana a la condición de que la proposición de ley fuera tomada en consideración por las Cortes Valencianas. Al igual que ocurre en LO 3/198422 o en la Ley catalana, esta indemnización no debería estar condicionada a la superación de la toma en consideración.

El criterio del Consell fue contrario a estas dos modificaciones. La no intervención de la Comisión Promotora en el trámite de la toma en consideración la justificó, tal y como he reproducido, atendiendo a la legitimidad democrática del Parlamento. Un claro brindis a la democracia representativa. Por su parte, la argumentación de la no modificación del momento en que la Comisión Promotora tiene derecho a una compensación por gastos reveló la desconfianza hacia la participación ciudadana en el proceso legislativo.

«...esta iniciativa va en contra de lo pretendido inicialmente en la propia Ley 5/1993, que con un criterio razonable sólo compensa las ILP que son tomadas en consideración, como medida para garantizar la seriedad de la iniciativa.. En efecto, como se expone en su preámbulo, esta condición, junto con los demás requisitos exigidos (...), tiene por objeto que no se produzcan gastos ni esfuerzos antes de tener clara la viabilidad de la propuesta de iniciativa, tanto desde el punto de vista técnico como del constitucional y estatutario. Al mismo tiempo, con la exigencia de la toma en consideración (...) se fomenta que los promotores realicen un estudio previo de la oportunidad de su proyecto." (BOCV 142, de 4 de marzo de 2002).

La proposición de ley sobre modificación de la Ley 5/93 no fue tomada en consideración por el Pleno de las Cortes Valencianas, en su sesión celebrada el día 24 de abril de 2002 (BOCV 149, de 6 de mayo de 2002). Una

22 Art. 15.1: "El Estado resarcirá a la Comisión Promotora de los gastos realizados en la difusión de la proposición y la recogida de firmas cuando alcance su tramitación parlamentaria". 
oportunidad perdida para mejorar nuestra Ley de iniciativa legislativa popular, la cual ha demostrado su inoperatividad.

Otra ocasión desaprovechada para modificar la obsoleta Ley 5/93 ha tenido lugar con la aprobación de la Ley 11/2008, de Participación Ciudadana de la Comunidad Valenciana. Esta Ley dedica un artículo, el 11, al Derecho a la iniciativa legislativa, que reza así: "Los ciudadanos y ciudadanas mayores de edad, que tengan la condición política de valencianos o valencianas, que estén inscritos en el censo electoral y que no estén privados de los derechos políticos, pueden ejercer ante Les Corts la iniciativa legislativa prevista en el artículo 26.2 del Estatut d'Autonomia de la Comunitat Valenciana, conforme a lo establecido en la normativa reguladora de la iniciativa legislativa popular. No introduce, por tanto, novedad alguna.

Debe procederse, a mi entender, de inmediato a modificar la Ley 5/93, reguladora de la Iniciativa Legislativa Popular de la Comunidad Valenciana, o, en su caso, a aprobar una nueva Ley que derogue la anterior. Es imprescindible, si realmente se desea potenciar la participación ciudadana en el proceso legislativo, a través de iniciativas populares, introducir cambios con relación a los requisitos materiales y formales y en la misma tramitación parlamentaria de estas Proposiciones de ley. Por tanto, también deberá modificarse el único artículo específico, el 126, del Reglamento de las Cortes Valencianas relativo a la tramitación de una iniciativa legislativa popular. Precepto que, recordémoslo, se limita a indicar que esta tramitación se ajustará a lo dispuesto para las proposiciones de ley.

Los comentarios sobre la Ley valenciana 5/93 son trasladables al resto de legislaciones de las Comunidades Autónomas reguladoras de la iniciativa legislativa popular.

\section{A MODO DE CONCLUSIÓN}

En las actuales democracias la participación ciudadana en la toma de decisiones políticas que afectan a la comunidad se ha venido realizando fundamentalmente a través de medios indirectos, siendo las elecciones el mecanismo principal de participación política. A través de las mismas elegimos a nuestros representantes, los cuales rendirán cuentas de su gestión al finalizar su mandato, siendo confirmados o removidos en unas nuevas elecciones. Esta democracia es calificada como representativa o electoral.

De acuerdo con el propio significado de la palabra democracia, cabría preguntarse en qué medida es democrática una democracia representativa. En este sentido, Robert Dahl utiliza el término poliarquía para referirse a estas democracias representativas, ya que entiende que la democracia, en el sentido etimológico del término (gobierno o poder del pueblo), no se daría en puridad en ningún Estado. Lógicamente, dado el tamaño de los Estados, no es concebible la democracia directa. Sin embargo sí es posible ampliar los cauces de participación ciudadana. Desde esta perspectiva, a partir de los 
años sesenta del pasado siglo, la doctrina, como fórmula intermedia entre la democracia directa y la representativa, concibe la denominada democracia participativa.

A nivel local, desde hace ya algunos años, se están desarrollando experiencias muy interesantes en materia de participación ciudadana. En este sentido, se han creado concejalías municipales de participación ciudadana y como iniciativa que involucra a los ciudadanos podríamos destacar, entre otras, la de los llamados "presupuestos participativos" (vgr. Municipios de Rubí, en Cataluña, o de Petrer, en la Comunidad Valenciana).

A nivel autonómico y estatal, la democracia participativa cuenta, sin duda alguna, con una importante institución de democracia semidirecta como es la iniciativa legislativa popular. Desgraciadamente, las leyes reguladoras de la iniciativa legislativa popular no han favorecido esta participación ciudadana en el ámbito legislativo, como lo demuestra el escaso número de iniciativas populares presentadas y, fundamentalmente, porque pocas de ellas logran su objetivo: convertirse en ley.

Esta inoperancia de la referida institución es achacable al legislador, tanto estatal como autonómico. El legislador ha sido renuente a que la ciudadanía participe en el proceso legislativo y esta actitud se tradujo en leyes reguladoras de iniciativas populares restrictivas de este derecho. No ha sido sino hasta el año 2006 que el legislador estatal y el catalán han modificado sus respectivas leyes de iniciativa popular con el objetivo de lograr su operatividad. Pese al poco tiempo transcurrido, estas reformas parecen haber aumentado la presentación de iniciativas populares.

Además de reformar las actuales leyes autonómicas relativas a esta institución de democracia semidirecta, también es necesario dar a conocer la misma a la ciudadanía, destacando su importancia. Esta tarea corresponde, obviamente, al ejecutivo, tanto estatal como autonómico. La democracia participativa debe arraigar entre la población.

A la hora de proceder a reformar las susodichas leyes autonómicas, deben tomarse en consideración, a nivel estatal, la Ley Orgánica 3/1984, de 26 de marzo, Reguladora de la Iniciativa Legislativa Popular, modificada por la Ley Orgánica 4/2006, de 26 de mayo, y, a nivel autonómico, la Ley de la Comunidad Autónoma de Cataluña 1/2006, de 16 de febrero, de la Iniciativa Legislativa Popular. La reforma operada en la ley estatal y la aprobación de la nueva ley catalana fueron, sin duda, una apuesta por la democracia participativa que está dando sus frutos: aumento de las iniciativas legislativas populares presentadas. Esperemos que la técnica del mimetismo funcione y todas las Comunidades Autónomas procedan a modificar sus respectivas leyes de iniciativas populares en los términos de la actual LO 3/1984 y de la Ley catalana 1/2006.

En conclusión, si realmente se quiere impulsar la participación ciudadana en las Comunidades Autónomas, una tarea urgente es la aprobación de nuevas Leyes de Iniciativa Legislativa Popular. Los objetivos de estas reformas serían: Que el número de proposiciones de ley de iniciativas legislativas populares aumente. Que la mayor parte de las iniciativas populares sean admi- 
tidas a trámite y que un número significativo de ellas alcance la tramitación parlamentaria, superando la toma en consideración de las Asambleas legislativas autonómicas. Que, por lo menos, algunas de estas iniciativas sean aprobadas finalmente por los parlamentos autonómicos.

TitLe: Popular legislative initiative in the Autonomous Regions. The necessary reform of their legislation

AвstRact: Article 86.3 of the Constitution grants citizens the right to participate in the legislative process through popular legislative initiatives. The Autonomous Statutes also contain this indirect democratic institution. In the context of the State, this institution is regulated by the Organic Law 3/1984, while each of the Autonomous Communities has passed the corresponding law on popular legislative initiative. These laws, both State and Autonomous, have been shown to be highly restrictive. Reform of the Popular Initiative Laws is therefore essential if we want the institution of citizen participation to function. The number of draft laws proposed should be significantly increased and after the necessary parliamentary debate a bigher number of such drafts should become law.

Resumen: El artículo 86.3 de la Contitución prevé la participación ciudadana en el proceso legislativo a través la iniciativa legislativa popular. En parangón a este precepto, los Estatutos de Autonomía también contemplan esta institución de democracia semidirecta. A nivel estatal, esta institución se reguló por la Ley Orgánica 3/1984, y posteriormente las Comunidades Autónomas fueron aprobando sus respectivas Leyes de iniciativa legislativa popular. Esta normativa, tanto estatal como autonómica, ha demostrado ser muy restrictiva. Por ello, la reforma de las Leyes de Iniciativa Popular se vuelve imprescindible si queremos que esta institución de participación ciudadana funcione, aumentando significativamente el número de proposiciones de ley y que éstas, tras su tramitación parlamentaria, se conviertan en leyes.

Key words: Popular initiative. Semi-direct democracy. Autonomous regions. Citizen participation.

Palabras clave: Iniciativa popular. Democracia semidirecta. Comunidades Autónomas. Participación ciudadana. 